\title{
Folga Orçamentária em uma Secretaria da Fazenda: um caso no nível do governo estadual no Brasil
}

\author{
Alyne Anteveli Osajima \\ Faculdade de Economia, Administração e Contabilidade de Ribeirão Preto da Universidade de \\ São Paulo \\ André Carlos Busanelli de Aquino \\ Faculdade de Economia, Administração e Contabilidade de Ribeirão Preto da Universidade de \\ São Paulo
}

\begin{abstract}
Organizações públicas vêm adotando modelos de mensuração de desempenho (MMD), a exemplo da iniciativa privada, buscando gerar incentivos à eficiência de equipes de servidores. A partir da literatura de folga orçamentária, este trabalho analisou o MMD de uma das Secretarias de Fazenda no nível estadual no Brasil e identificou que, a partir das metas pactuadas pela equipe diretiva da secretaria, a organização opera em um regime de folga orçamentária, em um ambiente organizacional de menor tensão em relação ao atingimento das metas e consequente gratificação. Através de séries históricas (jan./2007 a jun./2009) do desempenho individual mensal de 950 servidores públicos que atuam como fiscais, foram comparados o nível de atingimento das metas tributárias e administrativas. Adicionalmente, tais evidências foram trianguladas com observações participativas e análises documentais. Apesar da folga orçamentária detectada na utilização de metas com alta probabilidade de atingimento, o desempenho nas tarefas administrativas duplicou no último ano analisado, evidência de que o nível de esforço individual cresceu, apesar do incentivo pecuniário ser garantido em um nível menor de esforço.
\end{abstract}

Palavras-chave: folga orçamentária; setor público; modelo de mensuração de desempenho; governo estadual.

Holgura presupuestaria en el Departamento del Tesoro: un caso al nivel del gobierno estatal en Brasil

Las organizaciones públicas han ido adoptando sistemas de medición del desempeño (PMM, por sus siglas en inglés) a partir de los ejemplos de la iniciativa privada, buscando crear incentivos a la eficiencia de los equipos de funcionarios de carrera. Tomando como base los escritos sobre holgura presupuestaria, esta investigación ha analizado los PMM de un Departamento del Tesoro a nivel del gobierno estatal

Artigo recebido em 4 dez. 2011 e aceito em 5 out. 2012.

Rev. Adm. Pública - Rio de Janeiro 47(1):77-103, jan./fev. 2013 
en Brasil y ha determinado que, teniendo en cuenta el objetivo acordado por el equipo directivo del Tesoro, la organización opera en un régimen de holgura presupuestaria en un ambiente organizacional de menor presión en relación con la consecución de metas y sus consiguientes recompensas. A través de series históricas del rendimiento individual mensual de 950 funcionarios en su labor como fiscales, entre enero de 2007 y junio de 2009, se comparó el nivel de consecución de sus metas tributarias y administrativas. Además, se triangularon tales evidencias con las observaciones participativas y el análisis documental. A pesar de la holgura presupuestaria detectada en el uso de objetivos con una elevada probabilidad de éxito, el rendimiento en las tareas administrativas se duplicó en el último año analizado, lo cual evidencia que el nivel de esfuerzo individual aumentó a pesar del hecho de que el incentivo pecuniario está garantizado a un nivel de esfuerzo menor.

Palabras clave: holgura presupuestaria; sector público; sistema de medición del desempeño; gobierno del estado.

\section{Budgetary slack in a Treasury Department: a case in the state government level in Brazil}

Public organizations have been adopting performance measurement models (PMM), taking as example the private initiative, seeking to create incentives to the efficiency of servants teams. Based on the budgetary slack literature, this assignment analyzed the PMM of a Treasury Department in the state government level in Brazil and identified that, considering the goal agreed by the management team of the department, the organization operates in a regime of budgetary slack, in an organizational environment of lower pressure in relation of the goals achievement and consequent reward. Through historical series (Jan./2007 to June/2009) of the individual monthly performance of 950 civil servants acting as fiscals, it was compared the achievement level of the tributary and administrative goals. Additionally, such evidences were triangulated with participative observations and documental analysis. In spite of the budgetary slack detected in the use of goals with high achievement probability, the performance in the administrative tasks doubled in the last year analyzed, evidence that the individual effort level increased, despite the fact that the pecuniary incentive is guaranteed in a lower level of effort.

KEY WORDs: budgetary slack; public sector; performance measurement model; state government.

\section{Introdução}

Devido às crises econômicas, nas últimas décadas, os países estão passando por períodos de ajustamentos e os gastos públicos estão no centro desses esforços. Nesse aspecto, o orçamento público passa a ser um instrumento de controle, não do tipo político ou administrativo, mas sim econômico (Giacomoni, 2010). E esse é um dos esforços do movimento chamado New Public Management (NPM — Nova Gestão Pública), cujo começo é marcado por restrição fiscal (Kelly e Wanna, 2001). Iniciado por volta dos anos 1980, no Reino Unido, o movimento busca incorporar aos serviços públicos as práticas gerenciais da iniciativa privada para aumentar a eficiência dos serviços prestados. Assim, diante do aumento de responsabilidades, do maior controle sobre os gastos, enfim, diante de pressões por resultados sofridas pelo governo, o gestor passou a implantar esses sistemas para garantir um melhor desempenho. Entre as ferramentas importadas, destaca-se a implantação de modelos de mensuração de desempenho 
(MMD), vinculando a remuneração variável dos servidores ao cumprimento de metas (Hood, 1995; Ammons e Rivenbark, 2008; Lapsley, 2009).

$\mathrm{Na}$ iniciativa privada, pesquisadores já comprovaram que, em empresas que utilizam MMD, gestores estabelecem metas para serem facilmente atingidas, criando folga orçamentária (Van Der Stede, 2000; Aquino et al., 2008). Assim como, no setor público, pesquisas estão demonstrando que esse ambiente também é cercado de folga, seja ela gerencial ou orçamentária (O’Toole Jr. e Meier, 2010; Bruns e Himmler, 2011), e que, diante da busca por eficiência, a cada dia mais modelos de mensuração de desempenho são implantados em organizações públicas (Melkers e Willoughby, 2005), como também já observado no Brasil na Secretaria da Fazenda do Rio Grande do Sul (Freitas et al., 2009).

Decorrente das constatações apresentadas, esta pesquisa investigou a presença de folga orçamentária no modelo de mensuração de desempenho de uma Secretaria da Fazenda e discutiu alguns efeitos associados ao desempenho das tarefas. Para responder a essa questão, foi realizado um estudo documental em uma organização pública brasileira na esfera estadual. Trata-se de uma Secretaria da Fazenda que faz parte do Poder Executivo da administração direta do estado, exercendo como principal atividade a cobrança e a arrecadação de tributos estaduais. As análises documentais dos orçamentos públicos e a inserção no campo como observadora participante contribuíram para o entendimento da organização e a descrição do fenômeno. Para verificar se as metas estabelecidas pelo gestor eram facilmente atingíveis, caracterizando a existência de folga orçamentária, foram realizados testes de média da série histórica do desempenho individual dos servidores públicos submetidos ao MMD, no período de janeiro de 2007 a junho de 2009, variando de 508 a 634 servidores a cada período avaliado. $O$ teste não paramétrico Kruskal-Wallis foi utilizado para verificar se os desempenhos realizados diferenciaram-se na presença dos fatores nível de carreira, efeito sazonal e crise econômica.

Assim, o objetivo desta pesquisa foi investigar se existe folga orçamentária no MMD aplicado aos servidores públicos de uma Secretaria da Fazenda e verificar alguns fatores endógenos e exógenos associados ao desempenho de suas tarefas. Por isso foi escolhida uma organização pública que já implantou um MMD com remuneração variável dos servidores vinculada ao cumprimento de metas.

Diante deste cenário, o presente estudo busca contribuir com a literatura aplicada ao setor público, inclusive com o uso do estudo de campo, tão escasso entre os pesquisadores da área (Mckinnon, 1988), e que dá suporte para a riqueza de detalhes e maior entendimento do fenômeno (Humphrey e Scapens, 1996). Ao analisar um MMD de uma organização pública, esta pesquisa contribui para que os gestores públicos de outras administrações com características similares, como outras Secretarias da Fazenda do Estado brasileiro, reavaliem seus modelos de desempenho já implantados ou promovam adaptações para suas realidades, considerando os fatores que são ínsitos ao ambiente público. Isso poderá gerar maiores chances de sucesso na gestão e na eficiência nos serviços públicos prestados.

O desenvolvimento do trabalho apresenta-se dividido em seis partes. A primeira inclui essa introdução; a segunda é o referencial teórico e o desenvolvimento de hipóteses; a terceira apresenta a metodologia empregada; a quarta é a apresentação do caso do modelo de mensu- 
ração de desempenho da Secretaria da Fazenda em questão; a quinta é composta pelos testes e resultados e a sexta reúne as conclusões da pesquisa.

\section{Referencial teórico e hipóteses}

A cada dia, novas técnicas gerenciais vão sendo incorporadas com o intuito de melhorar a eficiência das organizações. Entre elas, destacam-se os MMDs, como o balanced scorecard. Por meio de indicadores de desempenho, metas são estabelecidas para promover o alinhamento do comportamento individual às estratégias de trabalho da empresa. Havendo recompensas ou punições associadas, estimulam os indivíduos a criarem metas mais fáceis de serem atingidas. Esses comportamentos disfuncionais, que afetam a relevância da informação para a tomada de decisão, desencadeiam o surgimento da folga orçamentária (Aquino et al., 2008; Epstein e Manzoni, 1997; Hopwood, 1987; Malina e Selto, 2001).

A folga orçamentária, ou budgetary slack, vem sendo objeto de várias pesquisas. Inicialmente, foi identificada como um problema decorrente dos estudos sobre orçamentos no ambiente privado. Segundo Lukka (1988), sua noção emergiu do estudo de Argyris, em 1952, e seguiu com diversos colaboradores, como Hopwood (1972), Osni (1973) e Merchant (1985), que prosseguiram com o tema. Considerado importante na seara orçamentária (Davila e Wouters, 2005), esse fenômeno é decorrente de ações intencionais dos gestores de elaborar metas facilmente atingíveis (Aquino et al., 2008). Sua constituição pode advir da subestimação de receitas, como também da superestimação de gastos e pedidos de recursos necessários para atingir as tarefas (Dunk e Nouri, 1998). No mesmo sentido, pode ser entendida como o excesso de montante orçamentário (Merchant, 1985), sinônimo de ineficiência (Borge et al., 2008) ou, até mesmo, atitude antiética (Douglas e Wier, 2000). Assim, advém de um comportamento disfuncional, fruto da interação dos gestores para atingirem as metas (Van Der Stede, 2000).

Desde Hopwood (1972), a literatura tem demonstrado interesse em entender os possíveis efeitos sobre o controle orçamentário no ambiente privado, como a folga orçamentária (Van Der Stede, 2000). Já no setor público, esse tema ainda se apresenta incipiente. Há na literatura algumas comprovações de folga orçamentária nesse ambiente. Fruto de manobras políticas (Bruns e Himmler, 2011) ou administrativas (Jacobsen, 2006), foi identificada como o resultado de um governo prudente que subestima a receita, cobre as despesas públicas e, ainda, constitui buffers (amortecedores) de precaução, sendo intensificada próxima às eleições (Ploeg, 2010). Outra evidência foi apontada por um legislador do Texas. Ao analisar o comportamento de seus agentes públicos, observou que, apesar de contestarem todos os anos de orçamentos apertados, ao final de cada período, suas metas eram atingidas tranquilamente (Meier e O'Toole Jr., 2009). Ainda, foi reduzida por eleitores de municípios noruegueses quando passaram a monitorar as contas públicas (Bruns e Himmler, 2011).

A folga orçamentária, por sua vez, também foi relacionada a resultados positivos com

o slack gerencial (folga na capacidade gerencial). Nos distritos escolares públicos dos Estados Unidos, selecionados por terem sofrido cortes elevados nas dotações orçamentárias, a presen- 
ça do slack gerencial amenizou os efeitos negativos da mudança. A folga, desta vez na capacidade do gestor, foi uma proteção contra a restrição no orçamento e impactou de maneira positiva o desempenho organizacional (O’Toole Jr. e Meier, 2010).

Portanto, constata-se que a literatura, tanto a voltada ao setor privado, quanto ao público, acaba utilizando vários significados para slack. Por exemplo, Aquino e colaboradores (2008) e Van der Stede (2000) seguem um entendimento de metas fixadas no orçamento para serem facilmente atingíveis. Já O’Toole Jr. e Meier (2010) relacionam essa folga com a capacidade gerencial da entidade. São abordagens diferentes, contudo convergem para a mesma ideia. Ou seja, excesso de recursos relacionados ao gerenciamento das atividades. Dessa forma, podem ser utilizadas como um buffer contra os maus tempos (Merchant, 1985).

Se a folga orçamentária é utilizada como amortecimento de fatores exógenos, e o MMD é baseado com mais peso em metas tributárias que envolvem resultados em autos de infração que, por sua vez, são fatores exógenos, dependentes de fatores de mercado, a hipótese é de que:

Hipótese 1: o modelo de mensuração de desempenho da Secretaria da Fazenda possua folga orçamentária de forma a continuar pagando gratificação mesmo com fatores exógenos.

O momento econômico pode influenciar mudanças na organização, ainda mais se relacionadas ao setor público. Receitas fiscais, por exemplo, são, em grande parte, impulsionadas pelo crescimento econômico. Por isso, especialistas, ao analisar o crescimento médio das receitas públicas, levam em consideração o fator cíclico (Thompson e Gates, 2007). Essa influência não se restringe apenas às entradas de recursos nos cofres públicos, também se estende às saídas. Governos de vários lugares do mundo, em decorrência das flutuações dos ciclos econômicos, sofrem restrições nas políticas fiscais (Fatás e Mihov, 2006).

Deste modo, a divisão dos períodos pode revelar ciclos ou, até mesmo, comportamentos. Em períodos de economia forte, por exemplo, gestores públicos adotam mais sistemas para medir desempenho, utilizando-os menos nas épocas de crise (Hou et al., 2011). Inclusive, esses períodos de choque importam. Podem gerar cortes de recursos, diminuição de despesas, enfim, afetar o desempenho da organização. É o que ocorreu no Texas. Num intervalo de oito anos, seus distritos escolares sofreram cortes no orçamento em decorrência dos choques econômicos, apresentando queda no desempenho (Meier e O’Toole Jr., 2009). Nesses casos, observa-se que o fator sazonal interferiu no desempenho da organização.

Assim, os períodos, sejam eles representados por meses, anos (Thompson e Gates, 2007), sejam eles decorrentes de choques ou crises econômicas (Meier e O’Toole Jr., 2009), podem influenciar a rotina das organizações e, por consequência, o desempenho dos funcionários. É esperado que também se encontre esse fenômeno ao analisar servidores que trabalham na Secretaria da Fazenda. Por se tratar de um órgão ligado ao ramo da política fiscal, responsável pela cobrança e arrecadação dos tributos, tende a reagir de acordo com os ciclos econômicos (Thompson e Gates, 2007) e outros efeitos sazonais (Hou et al., 2011). E como os trabalhos dos servidores relacionam-se a essa atividade-fim, seus desempenhos podem diferenciar-se na presença desses efeitos. A discussão precedente sugere a seguinte hipótese:

Hipótese 2: o atingimento das metas dos servidores públicos submetidos ao modelo de mensuração de desempenho seria afetado por fatores sazonais ou crise econômica. 
Os incentivos são utilizados nos contratos de trabalho no intuito de alinhar os interesses do empregado aos da empresa para obter melhores resultados (Besanko et al., 2007). Apesar das características ímpares dos contratos de trabalho dos servidores públicos, como a estabilidade de emprego (Mello, 2011), organizações públicas também dispõem de mecanismos para incentivar os servidores, devendo estar ligados ao pagamento ou representar uma forma de status aos servidores (Hou et al., 2011).

Entre os mais utilizados pelas organizações públicas, destaca-se o uso de promoções horizontais (Dixit, 2002) que afetam positivamente o desempenho dos indivíduos (Besanko et al., 2007) e da organização (Daley e Vasu, 2005). Isso ocorre porque os funcionários com preocupação na carreira estão interessados nos salários futuros, como também na reputação perante os demais colegas de trabalho (Autrey et al., 2007). Envolve prestígio, reconhecimento, além da realização pessoal (Clarke, 2009). Para isso, passa a contribuir potencialmente na execução das tarefas, acarretando aumento de seu desempenho e de sua organização (Dixit, 2002).

Apesar de a ascensão na carreira representar competência e merecimento, pode acarretar comportamentos maléficos à organização. Gestores com pretensão de horizonte na carreira ficam mais preocupados em alcançar as metas, por representar um fator determinante na promoção. Por conseguinte, ficam mais propícios a estabelecerem metas com folga no intuito de atingi-las. Isso porque, ao estabelecer metas mais fáceis de serem atingidas, demonstram a seus superiores que foram capazes de alcançá-las, ficando mais próximos de elevar-se hierarquicamente (Anderson et al., 2010).

Assim, um ambiente com progressão na carreira tanto pode desencadear o surgimento de folga orçamentária (Anderson et al., 2010), como também afetar positivamente o desempenho dos servidores (Besanko et al., 2007), funcionando como um estímulo para o cumprimento das metas. Inclusive, no caso em análise, observa-se que o nível de carreira pode acarretar desempenho diferente dos funcionários, decorrente tanto do acúmulo de conhecimentos adquiridos com a experiência quanto pela natureza das atividades exercidas conforme suas posições hierárquicas.

Na Secretaria da Fazenda, local de realização do estudo de campo, os servidores estão divididos em três níveis de carreira, que se diferenciam entre si. Não apenas pela exigência de tempo de serviço, como também pela natureza da atividade a ser executada. Ainda, a promoção para nível 2 e 3 não está associada ao desempenho. O fiscal aguarda o tempo mínimo e faz uma prova para progressão. Com metas iguais para todos os fiscais de todos os níveis, conforme prevê o modelo de desempenho, o grau de atingimento de metas passa a depender de incentivos extrínsecos e da facilidade relativa da tarefa. Como os níveis 2 e 3 fiscalizam empresas maiores, sendo selecionadas de forma randômica dentro do nível, apresentam uma economia de escala de esforço a ser realizado em uma fiscalização. Assim, se a determinação da empresa ocorre randomicamente para servidores do mesmo nível e as destinadas para o nível 3 são, em sua maioria, empresas de grande porte, demanda maior esforço do servidor do nível 1, comparado àqueles na carreira 2 e 3 . Então a hipótese é de que:

Hipótese 3: o atingimento das metas é diferente entre as carreiras e maior no nível 3. 


\section{Metodologia}

A coleta de dados documentais deu-se em duas etapas. A primeira envolveu visitas em campo, iniciada com a escolha do informante-chave. ${ }^{1}$ Em campo, foram realizadas visitas aos setores ligados ao orçamento (Tesouro Estadual) e à avaliação de desempenho (Coordenação do Sistema de Gratificação de Fiscalização). Em uma primeira etapa foram coletados os demonstrativos mensais contendo os desempenhos individuais de todos os servidores ativos integrantes da carreira fiscal no período de janeiro de 2007 a junho de 2009, totalizando inicialmente 950 fiscais, fornecidos em cópias eletrônicas, preservadas as identificações pessoais. Na segunda etapa, por meio de observação participante, o comportamento observado das metas e do desempenho realizado foi confrontado com a percepção do respondente-chave e o comportamento dos gestores em um período de um ano de negociação de metas e de avaliação de desempenho. Por fim, foram excluídos da amostra os servidores no exercício de função de chefia ou em gozo de férias com período superior a 15 dias no mês. Assim, o total de servidores passou, em média, para 580, oscilando em decorrência de alterações no quadro de pessoal, como férias e aposentadoria.

Dessa forma, totalizou um montante de 17.506 avaliações mensais, conforme tabela 1. Cada avaliação é expressa em uma meta e um desempenho realizado para um fiscal em determinado mês, de janeiro de 2007 a junho de 2009, para duas dimensões de avaliação: tarefas administrativas e tributárias (arrecadação), expressas em uma escala própria da Secretaria da Fazenda.

Tabela 1

Quantidade mensal de avaliações válidas de fiscais de jan./2007 a jun./2009*

\begin{tabular}{|cccccccccccccc|}
\hline Ano & Jan. & Fev. & Mar. & Abr. & Maio & Jun. & Jul. & Ago. & Set. & Out. & Nov. & Dez. & Total \\
\hline 2007 & 594 & 617 & 619 & 627 & 634 & 622 & 594 & 600 & 597 & 584 & 598 & 577 & 7263 \\
2008 & 563 & 576 & 617 & 590 & 600 & 596 & 570 & 594 & 592 & 597 & 592 & 572 & 7059 \\
2009 & 558 & 557 & 532 & 514 & 515 & 508 & - & - & - & - & - & - & 3184 \\
Total & 1715 & 1750 & 1768 & 1731 & 1749 & 1726 & 1164 & 1194 & 1189 & 1181 & 1190 & 1149 & 17506 \\
\hline
\end{tabular}

Fonte: Elaboração própria com base nos dados da Secretaria da Fazenda.

* A partir de jun./2009, a Secretaria da Fazenda não tinha os desempenhos individuais no sistema informatizado para serem analisados.

\footnotetext{
${ }^{1}$ Esse servidor foi escolhido pelo fato de já ter trabalhado em diversos departamentos da Secretaria da Fazenda, conhecer a organização, bem como os membros da equipe diretiva, facilitando o acesso aos dados. Contribuiu para o entendimento da secretaria e sua estrutura organizacional, dirimiu as dúvidas que iam surgindo, como também colaborou nas visitas aos departamentos, pois iniciava os contatos.
} 


\subsection{Análise descritiva}

A tabela 2 apresenta a estatística descritiva das variáveis que compõem o comportamento do desempenho dos fiscais no modelo de mensuração de desempenho da Secretaria da Fazenda. Todos os valores estão apresentados em escala numérica de pontuação, cuja meta varia de 0 a 2.000 pontos, e o realizado varia de 0 até o máximo de pontos atingidos pelo servidor, de acordo com suas tarefas e autos de infração lavrados.

Tabela 2

Análise descritiva da pontuação individual (meta e realizado) para tarefas administrativas (Adm.) e tributárias (Trib.)

\begin{tabular}{|llrrrrr|}
\hline Tarefa & Variáveis & $\mathrm{N}^{1}$ & Média & Desvio padrão & Mínimo & Máximo \\
\hline Adm. & Meta $\left(\right.$ mil pontos $\left.{ }^{2}\right)$ & 17506 & 0,97 & 0,09 & 0,464 & 1,00 \\
& Realizado $\left(\right.$ mil pontos $\left.{ }^{3}\right)$ & 17506 & 1,79 & 2,77 & 0,00 & 63,15 \\
& Atingimento $($ realizado/meta) & 17506 & 1,85 & 2,81 & 0,00 & 63,16 \\
Trib. & Meta $\left(\right.$ mil pontos $\left.{ }^{2}\right)$ & 17506 & 1,94 & 0,19 & 0,929 & 2,00 \\
& Realizado $\left(\right.$ mil pontos $^{3}$ ) & 17506 & 15,35 & 170,05 & 0,00 & $8.697,67$ \\
& Atingimento (realizado/meta) & 17506 & 7,98 & 85,26 & 0,00 & $4.348,84$ \\
Geral & Atingimento (realizado/meta) & 17506 & 8,97 & 85,26 & 0,00 & $4.349,84$ \\
\hline
\end{tabular}

Fonte: Elaboração própria com base nos dados da Secretaria da Fazenda com uso do software SPSSß para aplicação da análise descritiva. Notas:

1. Número de avaliações individuais válidas dos fiscais no período de jan./2007 a jun./2009.

2. Pontuação individual, com escala de 0 a 2.000. Os valores mínimos são proporcionais ao período trabalhado (férias).

3. Pontuação individual com escala de 0 até o máximo de pontos realizados (chegou a superar a meta mais de 4 mil vezes).

Na tabela 2, as médias das metas colocadas, tanto administrativas, quanto tributárias, se aproximam do máximo previsto no MMD (respectivamente 1.000 e 2.000 pontos). $\mathrm{O}$ valor mínimo de 464 para metas administrativas é referente a funcionários que gozavam férias no período. Essa característica estática das metas fornece indícios de folga. Segundo o informante-chave, os gestores não utilizavam esses resultados gerenciais de desempenho individual em suas avaliações. Os supervisores avaliavam os resultados de seus subordinados, mas suas análises não eram repassadas aos superiores. Ou seja, não havia interligação de informações entre supervisor e média e alta gerência, por isso as metas ficaram constantes. No período em análise, percebe-se que, na média, os servidores, de acordo com os autos de infração lavrados, apresentaram um desempenho nas tarefas tributárias quase oito vezes maior $(7,98)$ do que a meta estabelecida pelos gestores, fornecendo indícios de facilidade no alcance das metas. 
A análise descritiva da pontuação individual (metas e realizado) para tarefas administrativas por nível de carreira está disposta na tabela 3. Do total dos dados coletados, 8.403 avaliações individuais pertencem ao nível 1, outras 5.178 avaliações, ao nível 2, e o restante é do nível 3. Isso ocorre pois os cargos de chefia são conferidos, com maior frequência, para aqueles que estão no cargo intermediário ou final, o que os dispensa da avaliação do MMD. O cargo nível 1, início da carreira, obteve em média maior superação das metas (2,13 vezes), em relação aos cargos nível 2 (1,77 vez) e nível 3 (1,34 vez), sendo o desempenho inversamente proporcional ao nível de carreira. Servidores no início da carreira recebem mais tarefas procedimentais, como vistorias e atendimentos, e acabam apresentando melhores resultados nessas tarefas.

\section{Tabela 3}

Análise descritiva da pontuação individual (meta e realizado) para tarefas administrativas por nível de carreira

\begin{tabular}{|llccccc|}
\hline Nível & Variáveis & $\mathrm{N}^{1}$ & Média & Desvio padrão & Mínimo & Máximo \\
\hline 1 & Meta (mil pontos ${ }^{2}$ ) & 8403 & 0,986 & 0,073 & 0,464 & 1,000 \\
& Realizado (mil pontos ${ }^{3}$ ) & 8403 & 2,105 & 3,347 & 0,00 & 63,158 \\
& Atingimento (real/meta) & 8403 & 2,13 & 3,36 & 0,00 & 63,16 \\
2 & Meta (mil pontos ${ }^{2}$ ) & 5178 & 0,965 & 0,111 & 0,464 & 1,000 \\
& Realizado (mil pontos $\left.{ }^{3}\right)$ & 5178 & 1,687 & 2,452 & 0,00 & 42,301 \\
& Atingimento (real/meta) & 5178 & 1,77 & 2,55 & 0,00 & 42,30 \\
& Meta (mil pontos ${ }^{2}$ ) & 3925 & 0,961 & 0,115 & 0,464 & 1,000 \\
& Realizado (mil pontos ${ }^{3}$ ) & 3925 & 1,266 & 1,344 & 0,00 & 37,169 \\
& Atingimento (real/meta) & 3925 & 1,34 & 1,43 & 0,00 & 37,17 \\
\hline
\end{tabular}

Fonte: Elaboração própria com base nos dados da Secretaria da Fazenda com uso do software SPSS ${ }^{\circledR}$ para aplicação da análise descritiva. Notas:

1. Número de avaliações individuais válidas dos fiscais no período de jan./2007 a jun./2009 por nível de carreira.

2. Pontuação individual, com escala de 0 a 2.000. Os valores mínimos são proporcionais ao período trabalhado (férias).

3. Pontuação individual com escala de 0 até o máximo de pontos realizados (nível 1 chegou a atingir 63 vezes a meta).

Já para as tarefas tributárias, a tabela 4 apresenta a análise descritiva da pontuação individual (metas e realizado), também por nível de carreira. 
Tabela 4

Análise descritiva da pontuação individual (meta e realizado) para tarefas tributárias por nível e por atingimento geral (administrativas e tributárias)

\begin{tabular}{|c|c|c|c|c|c|c|}
\hline Nível & Variáveis & $\mathrm{N}^{1}$ & Média & Desvio padrão & Mínimo & Máximo \\
\hline \multirow[t]{4}{*}{1} & Meta (mil pontos²) & 8403 & 1,97 & 0,14 & 0,929 & 2,00 \\
\hline & Realizado (mil pontos³) & 8403 & 12,28 & 195,56 & 0,00 & $7.013,10$ \\
\hline & Atingimento (realizado/meta) & 8403 & 6,26 & 97,88 & 0,00 & $3.506,55$ \\
\hline & Atingimento geral ${ }^{4}$ & 8403 & 7,26 & 97,88 & 0,00 & $3.507,55$ \\
\hline \multirow[t]{4}{*}{2} & Meta (mil pontos²) & 5178 & 1,93 & 0,22 & 0,929 & 2,00 \\
\hline & Realizado (mil pontos ${ }^{3}$ ) & 5178 & 17,28 & 141,66 & 0,00 & $5.962,71$ \\
\hline & Atingimento (realizado/meta) & 5178 & 9,04 & 71,26 & 0,00 & $2.981,36$ \\
\hline & Atingimento geral ${ }^{4}$ & 5178 & 10,04 & 71,26 & 0,00 & $2.982,36$ \\
\hline \multirow[t]{4}{*}{3} & Meta (mil pontos²) & 3925 & 1,92 & 0,23 & 0,929 & 2,00 \\
\hline & Realizado (mil pontos ${ }^{3}$ ) & 3925 & 19,36 & 143,49 & 0,00 & $8.697,67$ \\
\hline & Atingimento (realizado/meta) & 3925 & 10,24 & 72,11 & 0,00 & $4.348,84$ \\
\hline & Atingimento geral ${ }^{4}$ & 3925 & 11,23 & 72,11 & 0,00 & $4.349,84$ \\
\hline
\end{tabular}

Fonte: Elaboração própria com base nos dados da Secretaria da Fazenda com uso do software SPSS ${ }^{\circledR}$ para aplicação da análise descritiva. Notas:

1. Número de avaliações individuais válidas dos fiscais no período de jan./2007 a jun./2009 por nível de carreira.

2. Pontuação individual com escala de 0 a 2.000. Os valores mínimos são proporcionais ao período trabalhado (férias).

3. Pontuação individual com escala de 0 até o máximo de pontos realizados (nível 3 chegou a atingir 4 mil vezes a meta).

4. Representa a soma do atingimento das tarefas administrativas e tributárias por nível de carreira.

Observa-se que o atingimento nessas tarefas acompanhou a ascensão na carreira, como pode ser constatado no comportamento de suas médias. Para todos os níveis o desempenho foi muito superior à meta. Fiscais do nível 3 de carreira tiveram um desempenho igual a 10 vezes o valor da meta $(10,24)$, enquanto do nível 1 e 2 alcançaram 6,26 e 9,04, respectivamente. À medida que cresce na carreira, aumenta o porte das empresas objetos de fiscalização, acarretando autuações com valores mais vultosos. 


\section{Apresentação da Secretaria da Fazenda e de seu modelo de mensuração de desempenho}

Cada uma das 27 unidades federativas do Brasil possui sua Secretaria da Fazenda, cuja principal atribuição é coordenar as atividades de arrecadação e cobrança dos tributos estaduais, sendo realizado o estudo em uma delas. Por meio de análises do orçamento público e visitas ao Tesouro Estadual, obteve-se conhecimento do processo orçamentário no nível organizacional. ${ }^{2}$ Pode-se observar que o valor destinado à Secretaria da Fazenda, definido na Lei Orçamentária Anual (LOA), não é decorrente da soma de todos os projetos planejados e previstos no Plano Plurianual (PPA). Muito pelo contrário, é fruto de ajustes dos recursos que ficaram disponíveis, após o abatimento das despesas de caráter obrigatório. Ou seja, o orçamento geral dessa secretaria sofre restrições de recursos.

A pressão sobre o orçamento público, exigindo contenções e reformas no setor, também acontece em outros países, como Estados Unidos, Canadá, Reino Unido (Leslie e Canwell, 2010; Roberts, 2003), sendo observada na Secretaria da Fazenda. No período de 2006 a 2010, diminuiu a disponibilidade de recursos nesse órgão. Com isso, exigiu-se eficiência no uso de recursos internos, seja por meio do controle mais efetivo nos materiais de consumo ou até mesmo nos litros de combustível por quilômetro rodado.

Já a demanda de suas atividades aumentou entre os anos de 2000 e 2010. Nesse período, só na função de fiscalização, por exemplo, a carga potencial de trabalho envolvido cresceu com o aumento de mais de $70 \%$ de contribuintes. Contudo, o número de fiscais alocados nessa função cresceu apenas $15 \%$. Essa diferença foi atenuada com o emprego de tecnologia para auxiliar a fiscalização, sendo implantada, por exemplo, a nota fiscal eletrônica.

Parte significativa da arrecadação dos impostos deste estado é decorrente do imposto sobre operações relativas à circulação de mercadorias e sobre prestação de serviços de transporte interestadual, intermunicipal e de comunicação (ICMS), com forte correlação positiva (0,9951), inclusive nos momentos de queda brusca, como em abril de 2006, conforme demonstra o comportamento das duas curvas do gráfico 1.

\footnotetext{
${ }^{2}$ Uma LOA é aprovada todo ano contendo a previsão de receitas e a fixação de despesas do estado. O valor da receita prevista é calculado pelo Tesouro Estadual e, depois, as despesas são fixadas no mesmo valor. Inicialmente, são consideradas as despesas de caráter obrigatório. Em seguida, o restante dos recursos disponíveis é dividido entre os órgãos do governo pela Secretaria do Planejamento e Desenvolvimento (Seplan). Definidas as cotas, esses valores são distribuídos pela Secretaria da Fazenda entre as ações e os programas de cada órgão de acordo com o previsto no PPA, instrumento orçamentário que contém metas e prioridades de médio prazo do governo. Depois, a LOA é submetida à aprovação na Assembleia Legislativa.
} 
Gráfico 1

Arrecadação realizada mensal dos tributos estaduais e o ICMS

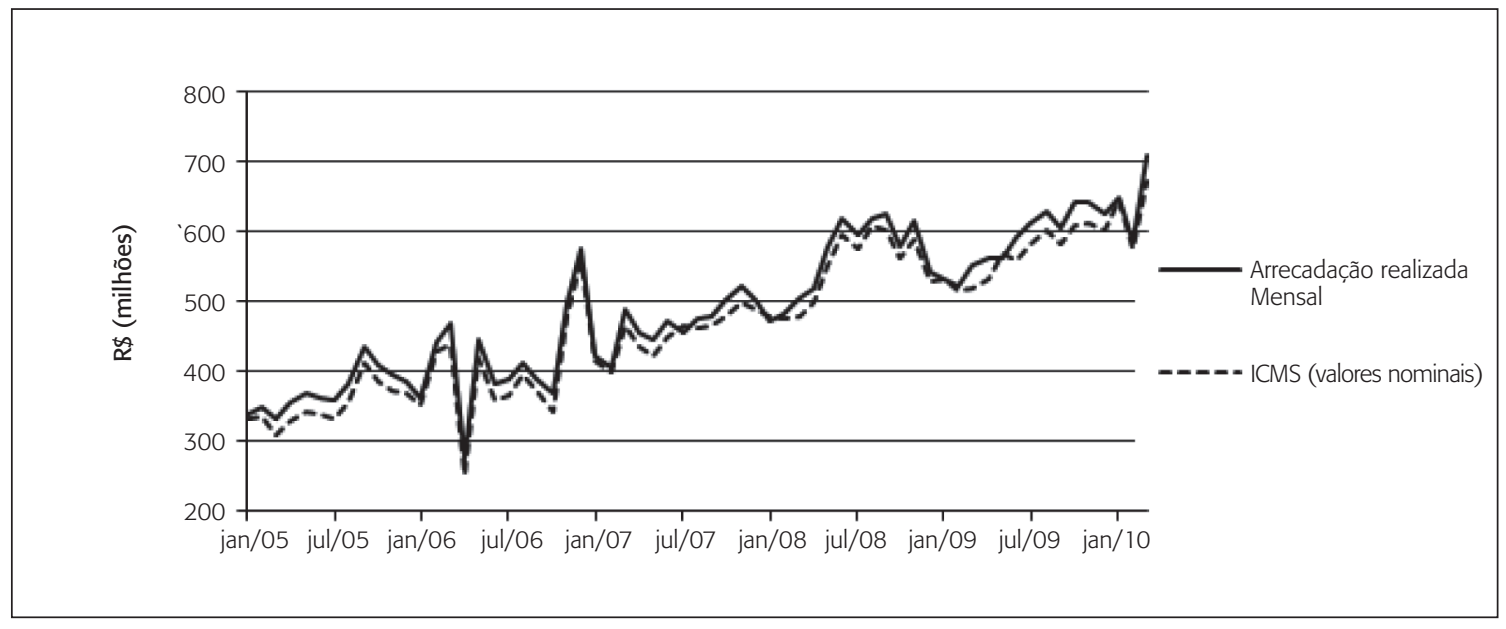

Fonte: Elaboração própria com base nos dados da Secretaria da Fazenda.

Comparando o crescimento do Produto Interno Bruto (PIB) do estado, informado pelo Instituto Brasileiro de Geografia e Estatística (IBGE), com os valores da receita tributária do estado, extraídos do banco de dados da Secretaria da Fazenda, observa-se que, no período entre 2005 e 2008, a receita estadual acompanhou paralelamente a linha de crescimento do PIB. Dentro desse período, o PIB cresceu 48,95\%, enquanto a receita cresceu 57,91\%. Esse resultado demonstra que, além da economia, as ações fiscalizadoras também contribuíram para seu bom desempenho.

Nesse ambiente, ao mesmo tempo que se procurou reduzir despesas e aumentar receitas, cresceu a demanda de suas atividades e restringiu a disponibilidade de recursos, demonstrando um ambiente com pressão orçamentária no nível organizacional. Ao mesmo tempo, estudos realizados na iniciativa privada já comprovaram que, em ambientes com pressão, supervisores estabelecem intencionalmente metas fáceis para serem atingidas, gerando folga orçamentária (Van Der Stede, 2000). O cenário encontrado nesse ambiente público apresenta evidências de que o fenômeno da folga possa existir no MMD implantado na Secretaria da Fazenda para avaliar o desempenho dos servidores.

\subsection{0 modelo de mensuração de desempenho da Secretaria da Fazenda}

Em 2005, a Secretaria da Fazenda instituiu um modelo de mensuração de desempenho vinculando o cumprimento de metas ao pagamento da remuneração variável de seus ser- 
vidores. Esta pesquisa focou os integrantes da carreira do fisco, representada pela classe de auditores fiscais que atuam na atividade-fim, ou seja, na fiscalização direta dos tributos estaduais.

O modelo, conhecido como Programa de Participação de Resultados, avalia o desempenho do servidor tanto por meio do trabalho em equipe quanto por meio do esforço individual. Se a equipe da Secretaria da Fazenda alcançar as metas previamente estabelecidas, cada membro receberá sua parte variável da remuneração levando-se em consideração o quanto contribuiu para o seu alcance. Ou seja, o cumprimento da meta coletiva é requisito para a concessão da gratificação. Os 100\% da remuneração variável são alcançados da seguinte forma: $60 \%$ por meio de meta coletiva para a Secretaria da Fazenda, ligada à arrecadação do estado, adquirida por aqueles que efetivamente trabalharam na equipe; $40 \%$ decorrentes do esforço individual. Dos 40\%, 28\% são associados à realização de tarefas administrativas, caracterizada por procedimentos formais, como o preenchimento de documentos, e $12 \%$ são associados ao efetivo output da função de fiscalização que foi exercida. São realizados por meio do desempenho de tarefas tributárias, vinculadas aos créditos tributários levantados nos autos de infração, ou seja, são medidos pelo montante em reais devido pela empresa fiscalizada.

Estes procedimentos individualizados são medidos pelo acúmulo de pontos associados ao cumprimento de tarefas desempenhadas no mês, controladas pelos relatórios de atividades preenchidos pelos servidores e revisadas pelo supervisor. Os pontos excedentes das tarefas tributárias, ligadas à arrecadação, podem ser utilizados para cumprimento das administrativas. Entretanto, o contrário não é permitido. Inclusive, a meta nestas tarefas representa o dobro da administrativa. O modelo visa incentivar as ações fiscalizadoras, que acarretem aumento de arrecadação, por isso atribui mais peso a elas.

As metas para a equipe da Secretaria da Fazenda são estabelecidas por uma comissão formada pelo secretário da Fazenda, sua equipe diretiva, três servidores representantes da carreira do fisco e mais dois representando a carreira do apoio fiscal. Fixam metas mínimas e máximas a serem atingidas por toda a equipe, tendo como indicador de desempenho a receita arrecadada pelo estado. Se a equipe atingir a meta mínima, um montante de recursos previamente estabelecido é distribuído entre os participantes, de acordo com o alcance de suas metas individuais. Se a equipe alcançar a meta máxima, acresce mais 10\% sobre esse valor. Essas metas não se confundem com as receitas previstas na LOA, que estima o montante de recursos que serão arrecadados pelo estado. Aqui, são previstas para fins gerenciais, ou seja, objetivam aumentar o desempenho da equipe incentivando-os com o pagamento da remuneração variável.

O gráfico 2 mostra que, para o período em questão, a arrecadação realizada (linha cheia) em geral é superior às metas mínimas de arrecadação (área cinza). 
Gráfico 2

Relação mensal entre as metas gerenciais de arrecadação dos impostos estaduais e a arrecadação realizada

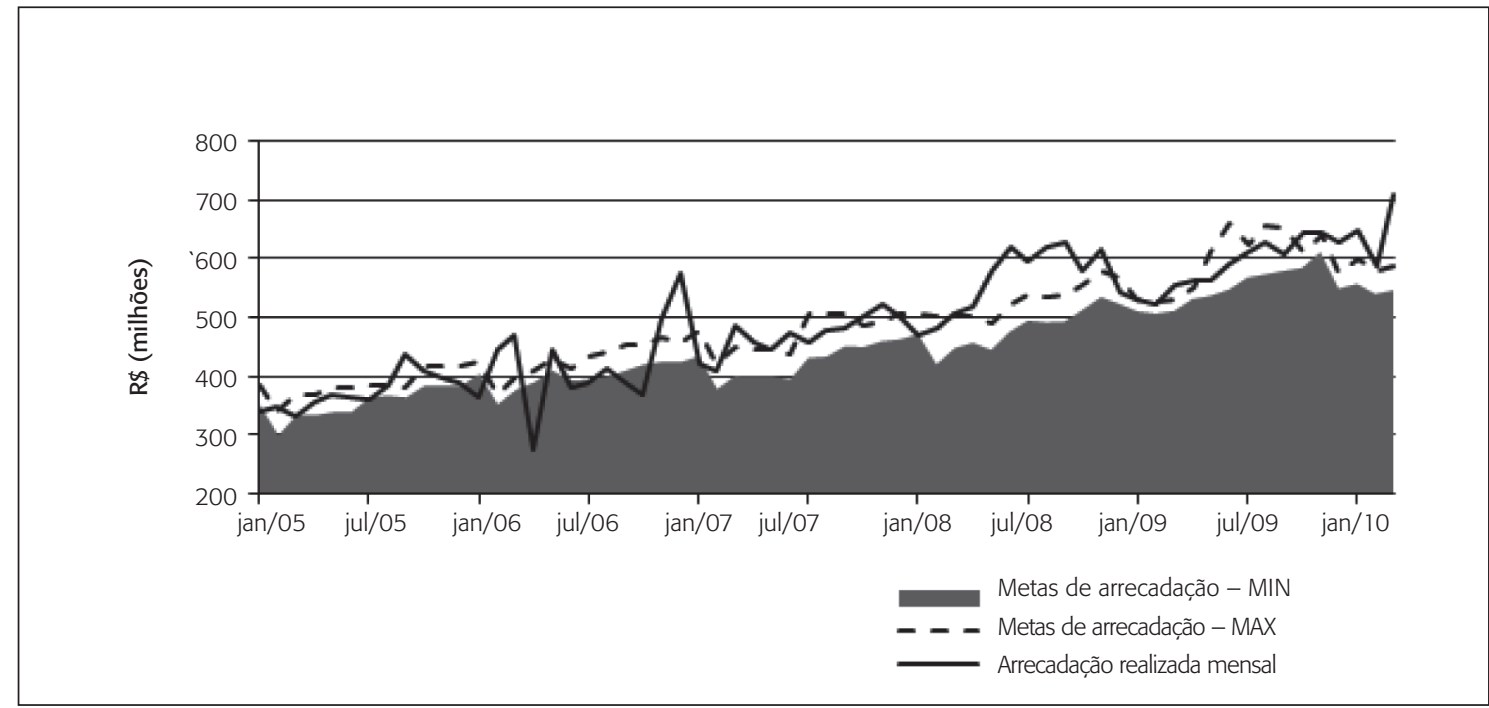

Fonte: Elaboração própria com base nos dados da Secretaria da Fazenda.

Observa-se no gráfico acima que, no período de 2005 a 2007, a meta máxima em geral foi estabelecida com excessiva rigidez. Já no período entre 2007 e 2009, aumentou a facilidade da equipe em atingir a meta. Isso ocorreu devido ao crescimento elevado em 2008, motivado principalmente pela cobrança de taxas decorrentes de benefícios fiscais e taxas para permissões de exploração de recursos naturais, conforme levantamentos dos valores das receitas tributárias. Observa-se que, no geral, a equipe atingiu a meta coletiva, ainda que no patamar da meta menor. Essa facilidade no alcance das metas coletivas indica a possibilidade de existência de folga inclusive nas metas no nível individual, objeto de análises estatísticas mais adiante.

O gráfico 3 apresenta a proporção da remuneração variável (gratificação) em relação ao salário base recebido pelo fiscal. Estes valores representam o peso dessa gratificação para um servidor que sempre atingiu a meta máxima individual. Na linha cheia do gráfico observa-se o comportamento da média trimestral, e, nas barras, o peso da gratificação na remuneração total do servidor para cada mês. Por exemplo, em junho de 2009, cada servidor que atingiu a meta máxima gerou mais de $80 \%$ do seu salário base em gratificação, ou seja, a remuneração variável representou cerca de $45 \%$ da remuneração total bruta do servidor. Ainda, desconsiderando os meses de pico, pode-se visualizar que a parte variável cresce em degraus ao longo do tempo, conforme demonstrado no gráfico com a linha média por ano. 
Representatividade da remuneração variável em relação ao salário fixo

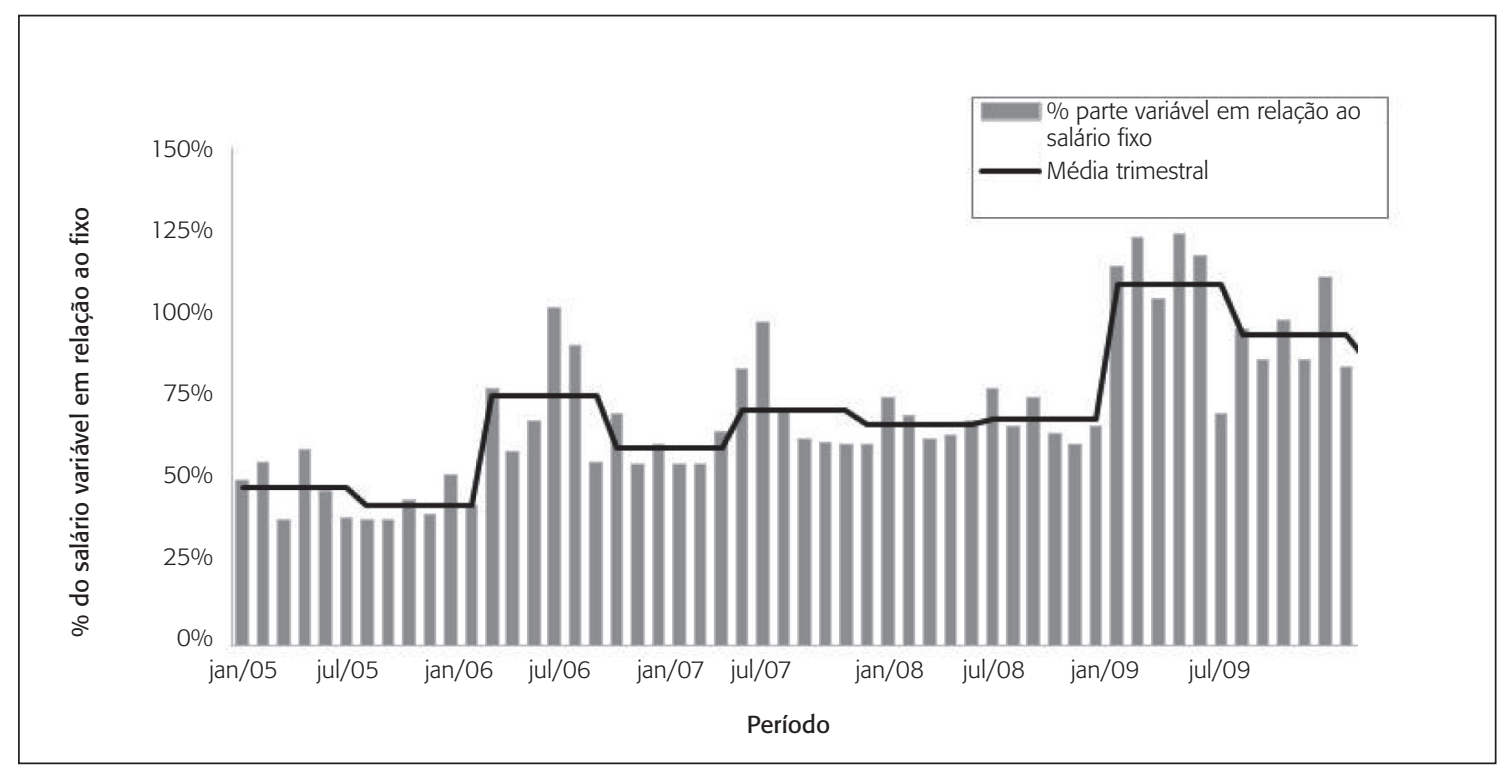

Fonte: Elaboração própria com base nos dados da Secretaria da Fazenda.

Nesse cenário, observa-se que a equipe sempre atingiu a meta coletiva, desencadeando pagamentos constantes das bonificações apenas para os servidores que atingiram suas metas individuais na vigência da aplicação do modelo. E, para esses que atingiram, suas remunerações variáveis tiveram considerável representação em relação à parte fixa. Essa elevada probabilidade de recebimento acabou virando uma certeza para os servidores, deixando dúvidas quanto ao real impacto do modelo em termos de incentivos.

\section{Testes e resultados}

Para testar a hipótese 1 foram aplicados testes de duas amostras, e a amostra atende aos pressupostos do teste $t$, pois a normalidade é exigida apenas para dimensões iguais ou inferiores a 30.

A tabela 5 demonstra que a média dos desempenhos realizados, tanto das tarefas administrativas $(F=4161,81$, Sig $=0,00)$, quanto das tributárias $(F=210,95$, Sig. $=0,00)$, difere da média de suas respectivas metas. Considerando um nível de significância de $5 \%$, pode-se afirmar que a hipótese nula de igualdade das metas foi rejeitada e que as amostras são estatisticamente diferentes. Conforme demonstrado na análise descritiva (tabela 2), a média do desempenho realizado nas tarefas, com destaque para as tributárias, foi bem acima da meta previamente estipulada pelos gestores, indicando metas com folga. 
Tabela 5

Teste $\mathrm{t}^{1}$ de duas amostras independentes das tarefas administrativas e tributárias

\begin{tabular}{|c|c|c|c|c|c|c|c|c|c|c|}
\hline & \multicolumn{3}{|c|}{$\begin{array}{c}\text { Teste Levene para } \\
\text { igualdade de variâncias }\end{array}$} & \multicolumn{7}{|c|}{ Teste t para igualdade de médias } \\
\hline & \multirow[b]{2}{*}{$I^{2}$} & \multirow[b]{2}{*}{$\mathrm{F}$} & \multirow[b]{2}{*}{ Sig. } & \multirow[b]{2}{*}{$\mathrm{T}$} & \multirow[b]{2}{*}{ gl. } & \multirow[b]{2}{*}{ Sig. ${ }^{3}$} & \multirow[b]{2}{*}{ Dif. médias } & \multirow{2}{*}{$\begin{array}{l}\text { Dif. Erro } \\
\text { padrão }\end{array}$} & \multicolumn{2}{|c|}{ 95\% I.C. da Dif. } \\
\hline & & & & & & & & & Abaixo & Acima \\
\hline Realizado & Sim & 4161,81 & 0,00 & $-39,10$ & 35010 & 0,00 & $-819,19$ & 20,95 & $-860,25$ & $-778,12$ \\
\hline Adm. & Não & & & $-39,10$ & 17547,76 & 0,00 & $-819,19$ & 20,95 & $-860,25$ & $-778,12$ \\
\hline Realizado & Sim & 210,95 & 0,00 & $-10,43$ & 35010 & 0,00 & $-13403,57$ & 1285,25 & $-15922,69$ & $-10884,44$ \\
\hline Tribut. & Não & & & $-10,43$ & 17505,04 & 0,00 & $-13403,57$ & 1285,25 & $-15922,78$ & $-10884,35$ \\
\hline
\end{tabular}

Fonte: Elaboração própria com base nos dados da Secretaria da Fazenda com uso do software SPSS $®$ para aplicação do teste de média. Notas:

1. 5\% nível de significância - Teste t para amostras independentes.

2. Igual variância assumida.

3. Sig. (2-caudas).

Foi aplicado o teste de média de uma amostra independente ao Atingimento de Meta (realizado/meta) e, a um nível de significância de 5\%, foi confirmada a hipótese alternativa de que as médias populacionais são iguais ou maiores que 1 (tabela 6). Assim, foi confirmado que as metas foram atingidas com facilidade pelos indivíduos submetidos à avaliação de desempenho, caracterizando folga orçamentária. Inclusive, tanto nas tarefas administrativas quanto nas tributárias, os valores das médias estão bem acima de 1 .

Tabela 6

Teste t de uma amostra independente das tarefas administrativas e tributárias

\begin{tabular}{|c|c|c|c|c|c|c|c|}
\hline & & \multicolumn{6}{|c|}{ Test Value $=1$} \\
\hline & & \multirow[b]{2}{*}{$\mathrm{T}$} & \multirow[b]{2}{*}{ gl. } & \multirow[b]{2}{*}{ Sig. (2-caudas) } & \multirow{2}{*}{$\begin{array}{l}\text { Diferença de } \\
\text { médias }\end{array}$} & \multicolumn{2}{|c|}{ 95\% I.C. da Dif. } \\
\hline & & & & & & Abaixo & Acima \\
\hline \multirow{2}{*}{$\begin{array}{l}\text { Atingimento (realizado/ } \\
\text { meta) }\end{array}$} & Adm & 39,85 & 17505 & 0,00 & 0,85 & 0,80 & 0,89 \\
\hline & Tribut & 10,83 & 17505 & 0,00 & 6,98 & 5,71 & 8,24 \\
\hline
\end{tabular}

Fonte: Elaboração própria com base nos dados da Secretaria da Fazenda com uso do software SPSS $®$ para aplicação do teste de média. Nota:

1. 5\% nível de significância - Teste t para uma amostra independente.

Por meio de observações das séries mensais (jan./2007 a jun./2009) dos indicadores de desempenho foi realizado um comparativo entre o realizado/meta, apresentado na tabela 7. 
Para cada período a tabela mostra a porcentagem de servidores que atingiram as metas. Em jan./2007, por exemplo, 98,5\% (80,3\%) dos servidores atingiram suas metas administrativas (tributárias). Ao final da tabela são apresentadas as médias para os 30 períodos.

Tabela 7

Porcentagem de metas atingidas das tarefas administrativas e tributárias por mês

\begin{tabular}{|c|c|c|c|c|c|c|c|c|}
\hline Período & $\begin{array}{l}\% \text { Ating. } \\
\text { T. Adm }\end{array}$ & $\begin{array}{l}\% \text { Ating. } \\
\text { T. Tribut. }\end{array}$ & Período & $\begin{array}{l}\% \text { Ating. } \\
\text { T. Adm }\end{array}$ & $\begin{array}{l}\% \text { Ating. } \\
\text { T. Tribut. }\end{array}$ & Período & $\begin{array}{l}\% \text { Ating. } \\
\text { T. Adm. }\end{array}$ & $\begin{array}{l}\% \text { Ating. } \\
\text { T. Tribut. }\end{array}$ \\
\hline Jan. 2007 & $98,5 \%$ & $80,3 \%$ & Jan. 08 & $98,8 \%$ & $86,1 \%$ & Jan. 09 & $99,5 \%$ & $88,5 \%$ \\
\hline Fev. 2007 & $98,7 \%$ & $79,9 \%$ & Fev. 08 & $99,7 \%$ & $82,5 \%$ & Fev. 09 & $98,7 \%$ & $87,8 \%$ \\
\hline Mar. 2007 & $99,5 \%$ & $82,1 \%$ & Mar. 08 & $98,1 \%$ & $80,6 \%$ & Mar. 09 & $99,2 \%$ & $89,8 \%$ \\
\hline Abr. 2007 & $99,2 \%$ & $83,4 \%$ & Abr. 08 & $99,7 \%$ & $87,3 \%$ & Abr. 09 & $99,2 \%$ & $89,7 \%$ \\
\hline Maio 2007 & $99,1 \%$ & $85,5 \%$ & Maio 08 & $99,0 \%$ & $88,0 \%$ & Maio 09 & $98,6 \%$ & $91,1 \%$ \\
\hline Jun. 2007 & $99,8 \%$ & $81,7 \%$ & Jun. 08 & $99,8 \%$ & $92,1 \%$ & Jun. 09 & $99,6 \%$ & $89,0 \%$ \\
\hline Jul. 2007 & $99,5 \%$ & $85,2 \%$ & Jul. 08 & $99,6 \%$ & $91,4 \%$ & \multicolumn{3}{|c|}{ Estatística Descritiva } \\
\hline Ago. 2007 & $98,8 \%$ & $87,2 \%$ & Ago. 08 & $99,2 \%$ & $91,1 \%$ & N (períodos) & 30 & 30 \\
\hline Set. 2007 & $99,7 \%$ & $84,6 \%$ & Set. 08 & $99,2 \%$ & $91,0 \%$ & Média & $99,1 \%$ & $86,2 \%$ \\
\hline Out. 2007 & $98,8 \%$ & $85,1 \%$ & Out. 08 & $98,5 \%$ & $88,3 \%$ & Mediana & $99,2 \%$ & $86,5 \%$ \\
\hline Nov. 2007 & $98,8 \%$ & $83,9 \%$ & Nov. 08 & $98,3 \%$ & $80,7 \%$ & Variância & $0,23 \%$ & $13,41 \%$ \\
\hline Dez. 2007 & $99,1 \%$ & $86,5 \%$ & Dez. 08 & $99,7 \%$ & $86,5 \%$ & Desvio Padrão & $0,48 \%$ & $3,66 \%$ \\
\hline
\end{tabular}

Fonte: Elaboração própria com base nos dados da Secretaria da Fazenda.

Com esse teste de frequência de atingimento de metas, desenvolvido por Walker e Johnson (1999), também utilizado por Aquino e colaboradores (2008), observa-se que as tarefas administrativas atingiram a meta 99,1\% das vezes e as tributárias, 86,2\%. Isso significa que a probabilidade de atingimento das metas para ambas as tarefas está bem acima dos 50\% que a literatura considera limite para metas difíceis (Merchant e Manzoni, 1989), sendo consideradas então metas facilmente alcançáveis.

Desta forma, ao relacionar os resultados apresentados nos testes de média, os quais comprovam que as médias dos desempenhos realizados são estatisticamente diferentes e superiores às metas estabelecidas pelos gestores, com o fato de que 99,1\% (86,2\%) das metas administrativas (tributárias) são atingidas pelos funcionários, comprova-se a existência de folga orçamentária no MMD da Secretaria da Fazenda, no período de janeiro de 2007 a junho de 2009. Portanto, esses resultados confirmam a hipótese 1. Ou seja, foi encontrada folga orçamentária no modelo de mensuração de desempenho da Secretaria da Fazenda e, por consequência, houve o pagamento da gratificação aos servidores. 


\subsection{Sazonalidade}

Para testar se o atingimento das metas seria afetado por fatores sazonais (hipótese 2), verificou-se primeiro a homogeneidade das matrizes de variância pelo teste não paramétrico Kruskal-Wallis. Esse teste é uma ferramenta alternativa para os casos em que nem todos os pressupostos da análise de variância são atendidos. O pressuposto do teste, igualdade de variância, foi atendido a um nível de significância de 5\%, conforme demonstra a tabela 8.

Tabela 8

\section{Teste de homogeneidade das matrizes de variância}

\begin{tabular}{|ccccc|}
\hline Variável & Estatística Levene $^{1}$ & gl1 & gl2 & Sig. \\
\hline Atingimento de Metas $^{2}$ & 2,81 & 2 & 17503 & 0,06 \\
\hline
\end{tabular}

Fonte: Elaboração própria com base nos dados da Secretaria da Fazenda com uso do software SPSS ${ }^{\circledR}$. Notas:

1. Testa a hipótese nula de matrizes de covariância populacionais iguais.

2. Referente à soma do atingimento das metas administrativas e tributárias.

Atendido o pressuposto anterior, foi avaliado se os desempenhos dos servidores diferenciaram-se com a presença de fatores sazonais exógenos, isolado, a cada teste, o elemento período (ano, semestre e bimestre). De acordo com a tabela 9, pode-se afirmar que a hipótese nula de igualdade de tendência central para todos os períodos foi rejeitada, comprovando-se estatisticamente que são diferentes, a um nível de significância de 5\%. A tabela 9 ainda apresenta os mesmos testes controlados por trimestre e mês, chegando-se aos mesmos resultados.

Tabela 9

Teste Kruskal-Wallis do atingimento das metas por ano, semestre e bimestre

\begin{tabular}{|c|c|c|c|c|c|c|c|c|c|c|}
\hline & \multirow[b]{2}{*}{ Período } & \multicolumn{3}{|c|}{ Teste Kruskal-Wallis } & \multicolumn{6}{|c|}{ Médias por período } \\
\hline & & Chi-quadrado & gl & Sig. & 1 & 2 & 3 & 4 & 5 & 6 \\
\hline \multirow[t]{3}{*}{ Atingimento de metas ${ }^{1}$} & $\mathrm{Ano}^{2}$ & 27,96 & 2 & 0,00 & 6,85 & 10,36 & 12,65 & & & \\
\hline & Semestre $^{3}$ & 13,62 & 1 & 0,00 & 8,79 & 10,10 & - & - & - & - \\
\hline & Bimestre $^{4}$ & 51,69 & 5 & 0,00 & 7,63 & 8,09 & 10,65 & 7,36 & 8,77 & 14,21 \\
\hline
\end{tabular}

Fonte: Elaboração própria com base nos dados da Secretaria da Fazenda com uso do software SPSS ${ }^{\circledR}$ para aplicação do teste estatístico. Notas:

1. Igual à soma do atingimento das tarefas administrativas e tributárias.

2. Variável de agrupamento: Anos de 2007, 2008 e 2009.

3. Variável de agrupamento: Semestre.

4. Variável de agrupamento: Bimestre.

As médias dos anos foram crescentes, 2007 no valor de 6,85, subindo para 10,36 no ano seguinte e, em 2009, ainda maior, 12,65. Dado que a meta é constante em todo o período, o 
comportamento do atingimento médio pode estar associado ao crescimento da economia do estado. Ao mesmo tempo que contribui para o crescimento da arrecadação estatal, gera um potencial crescimento da circulação de mercadorias e as transações efetuadas sem nota fiscal, por consequência eleva os números de autuações, tornando a meta mais fácil de ser alcançada com o decorrer dos anos. Além de variações anuais, alguns meses representados pelos bimestres na tabela 9 possuem maior folga, dada meta fixa em período e maior arrecadação, como as comemorações festivas dos meses de novembro e dezembro (bimestre 6), seguida de menor folga nos meses de janeiro e fevereiro (bimestre 1). Assim, aceita-se a hipótese 2, e as evidências de que o atingimento das metas dos servidores públicos submetidos ao MMD foi afetado por fatores sazonais.

\subsection{Crise econômica}

Para verificar se o desempenho dos servidores também foi afetado com outro fator exógeno, desta vez, crise econômica, foi aplicado o mesmo teste e controlados os meses de setembro, outubro e novembro de 2008, meses mais afetados pela crise financeira dos Estados Unidos. Conforme os resultados reproduzidos na tabela 10, os desempenhos realizados nos meses de crise apresentaram a mesma tendência central dos demais meses da amostra, sendo aceita a hipótese nula a um nível de significância de 5\%. Apesar de a crise refletir na redução de crédito e desaquecimento da demanda, de acordo com o PIB, o estado apresentou crescimento. Esses resultados comprovam que a hipótese 2 foi parcialmente rejeitada, ou seja, o atingimento das metas dos servidores públicos submetidos ao MMD não foi afetado pela presença de crise econômica.

Tabela 10

Teste Kruskal-Wallis do atingimento das metas nos meses de crise econômica

\begin{tabular}{|lccccccc|}
\hline & \multicolumn{3}{c}{ Teste Kruskal-Wallis $^{1}$} & & \multicolumn{3}{c|}{ Média dos meses } \\
\cline { 2 - 3 } & Chi-quadrado & Gl & Sig. & & Crise & Normal \\
\hline Atingimento de metas & & 0,53 & 1 & 0,47 & & 7,09 & 9,57 \\
\hline
\end{tabular}

Fonte: Elaboração própria com base nos dados da Secretaria da Fazenda com uso do software SPSS ${ }^{\circledR}$ para aplicação do teste estatístico.

Notas:

1. Variável de agrupamento: Ano.

2. Igual à soma do atingimento das tarefas administrativas e tributárias.

Por meio de análises documentais, constatou-se que, na época, foram utilizadas estratégias gerenciais para minimizar os efeitos da crise econômica, como a concessão de benefícios fiscais para incentivar o aumento de circulação de mercadorias. Ou seja, a presença do slack 
gerencial amenizou os efeitos negativos do desempenho organizacional por meio de decisões estratégicas (Meier et al., 2010; O’Toole Jr. e Meier, 2010). E isso também contribuiu para minimizar os efeitos maléficos desse período de crise econômica.

\subsection{Nível de carreira}

Para testar a hipótese de que a probabilidade do atingimento das metas seria diferente entre as carreiras, mostra-se (pelo teste Kruskal-Wallis, nível de significância de 5\%) que existe diferença das médias de atingimento entre os três níveis de carreira (tabela 11). Ainda, observa-se que, de acordo com as médias, os resultados alcançados melhoraram de acordo com a ascensão na carreira. O cargo final apresentou a maior média, pois, além do porte das empresas auditadas, agrega outros fatores, como o tempo de carreira, a experiência, enfim, um conjunto de atribuições adquiridas ao longo da carreira que acarretam aumento de produtividade. Os resultados apresentados também são consistentes com a hipótese 3.

Tabela 11

Teste Kruskal-Wallis do atingimento das metas por nível

\begin{tabular}{|lccccccccc|}
\hline & \multicolumn{3}{c}{ Teste Kruskal-Wallis $^{1}$} & & \multicolumn{3}{c|}{ Média por nível } \\
\cline { 2 - 3 } \cline { 5 - 7 } & Chi-quadrado & gl & Sig. & & 1 & 2 & 3 \\
\hline Atingimento de metas & & 1217,74 & 2 & 0,00 & & 7,26 & 10,04 & 11,23 \\
\hline
\end{tabular}

Fonte: Elaboração própria com base nos dados da Secretaria da Fazenda com uso do software SPSS ${ }^{\circledR}$ para aplicação do teste estatístico.

Notas:

1. Variável de agrupamento: Nível.

2. Igual à soma do atingimento das tarefas administrativas e tributárias.

O próprio plano de carreira em si é uma forma de motivação. Conforme se ascende na carreira, aumenta o valor dos vencimentos. No caso do serviço público, que possui estabilidade, associar o salário a um plano de carreira incentiva os servidores a realizarem suas tarefas com mais dedicação, melhorando seu desempenho. Segundo o informante-chave, outros fatores que influenciaram, além do pecuniário, seriam o status, o reconhecimento dos colegas e a autorrealização. É comum os funcionários fazerem comparações entre si. O desempenho apresentado no período é uma forma de exteriorizar o esforço e a capacitação associados à função, demonstrar aos colegas de trabalho suas capacidades, gerando reconhecimento. Consequentes melhorias nas atribuições e responsabilidades geram status e fazem com que o desempenho tenha alterações positivas. Por isso, o plano de carreira oferece um sentimento de ascensão contínua, sendo um instrumento de motivação. 


\subsection{Análise adicional}

Ocorre que, apesar de o modelo de avaliação conter metas com folga, o desempenho dos servidores continuou crescente. Os esforços associados à arrecadação são em função do PIB. Como 80\% da arrecadação do estado advém de ICMS, o aquecimento da economia aumenta a circulação de mercadorias, gerando o imposto devido e, proporcionalmente, cresce o montante potencial de sonegação. O desaquecimento produz incentivos à postergação do pagamento de impostos, mas não é claro se aumentaria a probabilidade de uma empresa optar pela sonegação. Assim, em um mesmo esforço feito pelo fiscal, o output desta tarefa de autuação fica associado ao desempenho positivo da economia e aos incentivos concedidos às indústrias e aos comércios em geral do estado. Por sua vez, o desempenho de tarefas administrativas depende basicamente do esforço do servidor, e seu desempenho médio mais que dobrou, conforme demonstrado no gráfico 4 (observa-se o significativo aumento da inclinação da curva a partir de maio de 2008).

Gráfico 4

Série de desempenho realizado das tarefas administrativas no período de jan./2007 a jun./2009

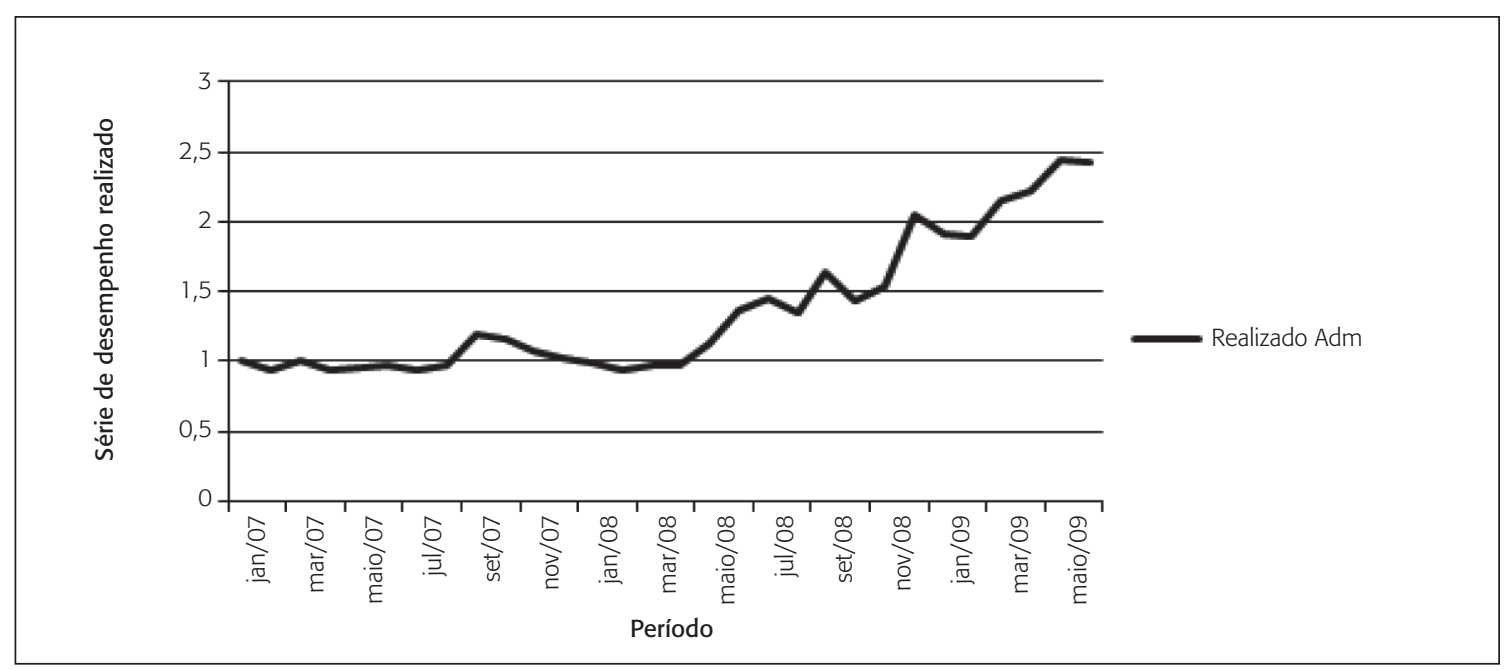

Fonte: Elaboração própria com base nos dados da Secretaria da Fazenda.

A gratificação é disparada pela meta geral da Secretaria da Fazenda, historicamente atingida (gráfico 2) e, em seguida, pela meta tributária individual dos fiscais que tem sido atingida, em média, de seis a 12 vezes. Em 2007, apenas 2,5\% dos servidores não atingiram a meta administrativa, e, em média, essa meta foi ultrapassada 99,1\% das vezes (tabela 7). Basta cumprir a meta mínima para garantir a maximização da remuneração. Há poucos incentivos ligados ao esforço da meta administrativa, sendo mais associados à meta tributária. 
Porém, mesmo com esta folga, a partir de jan./2008, o esforço em atividades que excedem o necessário para receber a gratificação máxima duplicou. Evidência de que, em geral, cumpriram a demanda de atividades que surgiam.

A princípio, um ambiente com essas características sofreria queda no desempenho (Davila e Wouters, 2005). Porém, com a facilidade no alcance das metas, os funcionários, sem recompensas diretas, despenderam esforços adicionais e cumpriram bem seus serviços. Essa atitude é condizente com o previsto na literatura sobre Public Service Motivation (PSM - Motivação do Serviço Público), que seria uma hipótese alternativa para explicar esse fenômeno. Nesta vertente, os funcionários são motivados a servir pelo bem do interesse público, sendo um fator inerente às organizações públicas (Leisink e Steijn, 2009; Kim, 2009; Perry e Wise, 1990). Além das recompensas extrínsecas, o desempenho alcançado pelos servidores seria influenciado por fatores intrínsecos (Bright, 2009), independente da remuneração variada (Marsden e Richardson, 1994). As características individuais, como assumir o compromisso com o interesse público (Houston, 2006) e com a sociedade (Lee e Wilkins, 2011), buscando a própria eficiência e a de sua organização (Bright, 2008), colaboraram para a realização dos trabalhos.

Adicionalmente a oportunidade que, além de satisfazer as necessidades, seja compatível com valores pessoais (Lee e Wilkins, 2011) e consequente identificação com a missão da organização aumentam a motivação intrínseca para realização dos trabalhos (Moynihan e Pandey, 2007; Wright, 2007; Wright e Pandey, 2008).

Por fim, destaca-se que a natureza das tarefas realizadas deve ser considerada. Comparada a outras secretarias, como a da Saúde, órgãos que apresentam maior dificuldade de mensuração de output, a Secretaria da Fazenda apresenta a vantagem de ter medidas de desempenho mais claras, já que utiliza a arrecadação como principal indicador de desempenho de sua equipe de trabalho. Esse critério facilita a avaliação objetiva dos outputs principais do órgão. A Secretaria de Segurança Pública, por exemplo, para avaliar a qualidade do sistema prisional deve utilizar sistemas de medição de desempenho mais complexos, comparados à objetividade utilizada na Secretaria da Fazenda. Entretanto, o uso exclusivo ou com mais ênfase em medidas quantitativas pode fazer com que os gestores deem menos atenção a outros objetivos, como a qualidade dos serviços prestados. Assim, a natureza objetiva da tarefa, em comparação com outras secretarias, ao mesmo passo que permite uso de medida de output como base principal de desempenho sem grandes perdas, em relação às medidas de outcome, o MMD pode estar inibindo esforço em ações que geram valor de longo prazo com base de inovação, visto que é privilegiado o curto prazo e são valorizadas eventuais inovações, em relação ao ato da fiscalização.

\section{Conclusão}

Este estudo buscou investigar a presença de folga orçamentária no modelo de mensuração de desempenho da Secretaria da Fazenda e discutiu alguns efeitos associados ao desempenho 
das tarefas. Para isso, foi realizada uma análise documental no caso do MMD da Secretaria da Fazenda de um dos estados do Brasil que já implantou esse modelo, vinculando a remuneração variável dos servidores ao cumprimento de metas.

Os resultados da pesquisa revelam que, em média, 92,65\% das metas gerais estabelecidas pelos gestores foram atingidas pelos funcionários. Inclusive, as médias dos desempenhos realizados foram estatisticamente diferentes e superiores às médias das metas. Dessa forma, a exemplo da experiência da Secretaria da Fazenda do Rio Grande do Sul (Freitas et al., 2009), observa-se folga orçamentária no MMD dos fiscais desta Secretaria da Fazenda.

O desempenho dos servidores nas tarefas administrativas foi crescente, o que chama especial atenção na pesquisa. Apesar de o modelo conter metas com folga, a falta de incentivos pecuniários não inibiu o crescimento do nível de esforço nessas tarefas. Ou seja, mesmo com a facilidade no alcance das metas, os funcionários, sem recompensas diretas, despenderam esforços adicionais e cumpriram bem seus serviços. Esse comportamento demonstra que o incentivo de natureza financeira não foi a única fonte incentivadora nesse órgão do governo. O desempenho pode ter sido impulsionado pela motivação do serviço público, independentemente do incentivo formal, cujo grau de impacto poderia ser futuramente testado com experimento que captasse o nível de PSM dos fiscais.

Neste caso, não se pode afirmar que a presença de folga orçamentária prejudicou o desempenho da Secretaria da Fazenda. Mas, ao contrário, é factível ponderar que a presença desse amortecedor, sobretudo nas metas gerais da equipe de fiscais, pode ser um elemento estabilizador que sinalizará aos fiscais que, apesar de fatores exógenos, eles podem despender seus melhores esforços para executar suas autuações e demais atividades que terão recompensas associadas. Obviamente, poderia ser discutido o limite mínimo, ou seja, se em vez de uma folga de seis vezes, uma de duas vezes não seria mais apropriadamente desafiadora. Ou a formação de áreas de responsabilidade e criação de equipes menores com suas metas e recompensas segmentadas.

Por fim, de forma geral, o setor público é composto por muitos órgãos de naturezas complexas, igualmente as secretarias supracitadas. Ao mesmo tempo, também é composto por unidades mais técnicas, com metas mais objetivas, como a da Fazenda. Consequentemente, a folga orçamentária encontrada no modelo de mensuração de desempenho aplicado aos fiscais desta Secretaria da Fazenda, de natureza mais objetiva, pode não ser encontrada com a mesma clareza, utilizando os mesmos métodos, em outros órgãos de naturezas mais complexas. As metas, assim como os MMD, podem ser diferentes. Dependendo da natureza da atividade exercida, trabalham com indicadores de desempenhos diferentes, uns mais, outros menos objetivos.

Embora os resultados não sejam diretamente generalizáveis a outras organizações públicas, o estudo aponta que há fatores que são ínsitos nas organizações do setor público e que, comparados ao setor privado, podem ter feito a diferença no desempenho. 


\section{Referências}

AMMONS, David N.; RIVENBARK, William C. Factors influencing the use of performance data to improve municipal services: evidence from the North Carolina Benchmarking Project. Public Administration Review, v. 68, n. 2, p. 304-318, 2008.

ANDERSON, Shannon W. et al. An empirical examination of goals and performance-to-goal following the introduction of an incentive bonus plan with participative goal setting. Management Science, v. 56, n. 1, p. 90-109, 2010.

AQUINO, André C. B. et al. Causality in a performance measurement model: a case study in a Brazilian power distribution company. Studies in Managerial and Financial Accounting - Performance Measurement and Management Control: Measuring and Rewarding Performance, Emerald Group Publishing Limited, v. 18, n. 1, p. 273-200, 2008.

AUTREY, Romana L. et al. Career concerns and mandated disclosure. Journal of Accounting and Public Policy, v. 26, p. 527-554, 2007.

BESANKO, David et al. Economics of strategy. $4^{\text {th }}$ ed. Nova York: John Wiley, Sons, 2007.

BORGE, Lars-Erik et al. Public sector efficiency: the roles of political and budgetary institutions, fiscal capacity, and democratic participation. Public Choice, v. 136, p. 475-495, 2008.

BRIGHT, Leonard. Does public service motivation really make a difference on the job satisfaction and turnover intentions of public employees? American Review of Public Administration, v. 38, n. 2, p. 149-166, 2008.

BRIGHT, Leonard. Why do public employees desire intrinsic non-monetary opportunities? Public Personnel Management, v. 38, n. 3, p. 15-38, 2009.

BRUNS, Christian; HIMMLER, Oliver. Newspaper circulation and local government efficiency. The Scandinavian Journal of Economics, v. 13, n. 2, p. 470-492, 2011.

CLARKE, Marilyn. Plodders, pragmatists, visionaries and opportunists: career patterns and employability. Career Development International, v. 14, n. 1, p. 8-28, 2009.

DALEY, Dennis M.; VASU, Michael L. Supervisory perceptions of the impact of public sector personnel practices on the achievement of multiple goals: putting the strategic into human resource management. The American Review of Public Administration, v. 35, n. 2, p. 157-167, 2005.

DAVILA, Tony; WOUTERS, Marc. Managing budget emphasis through the explicit design of conditional budgetary slack. Accounting, Organizations and Society, v. 30, p. 587-608, 2005.

DIXIT, Avinash. Incentives and organizations in the public sector: an interpretative review. The Journal of Human Resources, v. 37, n. 4, p. 696-727, 2002.

DOUGLAS, Patricia C.; WIER, Benson. Integrating ethical dimensions into a model of budgetary slack creation. Journal of Business Ethics, v. 28, p. 267-277, 2000. 
DUNK, Alan. S.; NOURI, Houssein. Antecedents of budgetary slack: a literature review and synthesis. Journal of Accounting Literature, v. 17, p. 72-96, 1998.

EPSTEIN, Marc J.; MANZONI, Jean-François. The balanced scorecard and tableau de board: translating strategy into action. Management Accounting, v. 79, p. 28-36, 1997.

FATÁS, Antonio; MIHOV, Ilian. The macroeconomic effects of fiscal rules in the US states. Journal of Public Economics, v. 90, p. 101-117, 2006.

FREITAS, Vinicius P. et al. Mensuração de desempenho em organizações públicas: o caso da Secretaria da Fazenda do Rio Grande do Sul. Revista do Serviço Público, v. 60, p. 277-290, 2009.

GIACOMONI, James. Orçamento público. São Paulo: Atlas, 2010.

HOOD, Christopher. The "New Public Management" in the 1980s: variations on a theme. Accounting, Organizations and Society, v. 20, n. 2-3, p. 93-109, 1995.

HOPWOOD, Anthony. An empirical study of the role of accounting data in performance evaluation. Journal of Accounting Research, v. 10, p. 56-182, 1972.

HOPWOOD, Anthony. The archaeology of accounting systems. Accounting, Organizations and Society, v. 12, n. 3, p. 207-234, 1987.

HOU, Yilin et al. State performance-based budgeting in boom and bust years: an analytical framework and survey of the States. Public Administration Review, v. 71, n. 3, p. 370-388, 2011.

HOUSTON, David J. "Walking the walk" of public service motivation: public employees and charitable gifts of the time, blood, and money. Journal of Public Administration Research and Theory, v. 16, n. 1, p. 67-86, 2006.

HUMPHREY, Christopher; SCAPENS, Robert W. Theories and case studies of organizational accounting practices: limitation or liberation? Accounting, Auditing and Accountability Journal, v. 9, n. 4, p. 86-106, 1996.

JACOBSEN, Dag I. Public sector growth: comparing politicians' and administrators' spending preferences. Public Administration, v. 84, n. 1, p. 185-204, 2006.

KELLY, Joanne; WANNA, John. A nova gestão pública e as políticas de programação orçamentária do governo. Revista do Serviço Público, n. 3, p. 52-81, jul./set. 2001.

KIM, Sangmook. Testing the structure of public service motivation in Korea: a research note. Journal of Public Administration Research and Theory, v. 19, n. 14, p. 839-851, 2009.

LAPSLEY, Irvine. New public management: the cruellest invention of the human spirit? A Journal of Accounting, Finance and Business Studies, v. 45, n. 1, p. 1-21, 2009.

LEE, Young-Joo; WILKINS, Vicky M. More similarities or more differences? Comparing public and nonprofit manager's job motivations. Public Administration Review, v. 71, n. 1, p. 45-56, 2011.

LEISINK, Peter; STEIJN, Bram. Public service motivation and job performance of public sector employees in the Netherlands. International Review of Administrative Sciences, v. 75, n. 1, p. 35-52, 2009. 
LESLIE, Keith; CANWELL, Adam. Leadership at all levels: leading public sector organizations in an age of austerity. European Management Journal, v. 28, n. 4, p. 297-305, 2010.

LUKKA, Kari. Budgetary biasing in organizations: theoretical framework and empirical evidence. Accounting Organizations and Society, v. 13, n. 3, p. 281-301, 1988.

MALINA, Mary A.; SELTO, Frank H. Communicating and controlling strategy: an empirical study of the effectiveness of the balanced scorecard. Journal of Management Accounting Research, v. 13, p. 441-469, 2001.

MARSDEN, David; RICHARDSON, Ray. The effects of "merity pay" on motivation in a public service. British Journal of Industrial Relations, v. 32, n. 2, p. 243-261, 1994.

MCKINNON, Jill. Reliability and validity in field research: some strategies and tactics. Accounting, Auditing and Accountability Journal, v. 1, p. 34-54, 1988.

MEIER, Kenneth J.; O'TOOLE JR., Laurence J. The dog that didn't bark: how public managers handle environmental shocks. Public Administration, v. 87, p. 485-502, 2009.

MEIER, Kenneth J.; O'TOOLE JR., Laurence J.; HICKLIN, Alisa. I've seen fire and I've seen rain: public management and performance after an natural disaster. Administration and Society, v. 41, p. 979-1003, 2010.

MELKERS, Julia; WILLOUGHBY, Katherine. Models of performance-measurement use in Local Governments: understanding budgeting, communication, and lasting effects. Public Administration Review, v. 65, n. 2, p. 180-190, 2005.

MELLO, Celso A. B. Curso de direito administrativo. São Paulo: Malheiros, 2011.

MERCHANT, Kenneth A. Budgeting and the propensity to create budgetary slack. Accounting, Organizations and Society, v. 10, n. 2, p. 201-210, 1985.

MERCHANT, Kenneth A.; MANZONI, Jean-François. The achievability of budget targets in profit centers: a field study. The Accounting Review, v. 64, n. 3, p. 539-559, 1989.

MOYNIHAN, Donald P.; PANDEY, Sanjay K. The role of organizations in fostering public service motivation. Public Administration Review, v. 67, n. 1, p. 40-53, 2007.

O'TOOLE JR., Laurence J.; MEIER, Kenneth J. In defense of bureaucracy: public managerial capacity, slack, and the Dampening of environmental shocks. Public Management Review, v. 12, p. 341-361, 2010.

OSNI, Mohamed. Factor analysis of behavioral variables affecting budgetary slack. The Accounting Review, v. 48, n. 3, p. 535-548, 1973.

PERRY, James L.; WISE, Lois R. The motivational basis of public service. Public Administration Review, v. 50, p. 367-373, 1990.

PLOEG, Frederick V. D. Political economy of prudent budgetary policy. International Tax and Public Finance, v. 17, p. 295-314, 2010. 
PROWSE, Peter; PROWSE, Julie. The dilemma of performance appraisal. Measuring Business Excellence, v. 13, n. 4, p. 69-77, 2009.

ROBERTS, Alasdair. In the eye of the storm? Societal aging and the future of public-service reform. Public Administration Review, v. 63, n. 6, p. 720-733, 2003.

THOMPSON, Fred; GATES, Bruce L. Betting on the future with a cloudy crystal ball? How financial theory can improve revenue forecasting and budgets in the states. Public Administration Review, v. 67 , n. 5, p. $825-836,2007$.

VAN DER STEDE, Wim A. The relationship between two consequences of budgetary controls: budget slack creation and managerial short-term orientation. Accounting, Organizations and Society, v. 25, p. 609-622, 2000.

WALKER, Kenton B.; JOHNSON, Eric N. The effects of a budget-based incentive compensation scheme on the budgeting behavior of managers and subordinates. Journal of Management Accounting Research, v. 11, p. 1-29, 1999.

WRIGHT, Bradley E. Public service and motivation: does mission matter? Public Administration Review, v. 67, n. 1, p. 54-64, 2007.

WRIGHT, Bradley E.; PANDEY, Sanjay K. Public service motivation and the assumption of personorganization fit: testing the mediating of value congruence. Administration and Society, v. 40, n. 5, p. 502-521, 2008.

Alyne Anteveli Osajima é mestre em controladoria e contabilidade pela Faculdade de Economia, Administração e Contabilidade de Ribeirão Preto da Universidade de São Paulo (FEA-RP/USP). E-mail: lyosajima@yahoo.com.br.

André Carlos Busanelli de Aquino é professor associado da FEA-RP/USP. E-mail: aaquino@usp.br. 